\title{
El espacio de la trata de personas con fines de explotación sexual. Sus representaciones en Argentina, a comienzos del siglo XXI
}

The space of human trafficking for sexual exploitation. Their representations in Argentina, at the beginning of the 21st century.

\section{Magdalena Moreno}

Centro de Investigaciones Geográficas/Instituto de Geografía Historia y Ciencias Sociales/ Universidad Nacional del Centro de la Provincia de Buenos Aires/CONICET, Argentina magdalenamorenoivan@gmail.com

\section{Resumen:}

En el artículo se analizan las representaciones del espacio producidas sobre la trata de personas con fines de explotación sexual en Argentina, entre 2008 y 2018. Para dicho análisis se retoman las ideas sobre la producción del espacio de Henri Lefebvre y, específicamente, el concepto representaciones del espacio, para leer algunas de las cartografías elaboradas por organismos estatales y asociaciones civiles. En un primer momento se presenta brevemente una definición sobre la trata de personas y la conceptualización de Lefebvre. En un segundo momento se muestran las cartografías que representan espacialmente al fenómeno de la trata de personas a escala nacional, obtenidas a partir del análisis documental, para luego analizar la espacialidad que crean. A continuación, se presenta la campaña antitrata, y, para concluir, se plantea el vínculo entre esta y las representaciones del espacio de la trata de personas, en relación a los posibles imaginarios geográficos que pueden configurarse.

PALABRAS ClAVE: Representaciones del espacio, Imaginarios geográficos, Trata de personas.

\section{ABstract:}

The article analyzes the representations of space produced on human trafficking for sexual exploitation in Argentina, between 2008 and 2018. For this analysis, the ideas of Henri Lefebvre about the production of space, and specifically the concept of space representations, are taken to read some of the cartographies elaborated by state organisms and civil associations. At first, a definition of human trafficking and Lefebvre's conceptualization are briefly presented. After that, the cartographies that spatially represent the phenomenon of human trafficking on a national scale, obtained from documentary analysis, are shown to analyze the spatiality they create. Next, the anti-trafficking campaign is presented; to conclude, the link between the latter and representations of the space of human trafficking is posited, in relation to the possible geographical imaginaries that can be configured.

KEYWORDS: Representations of space, Geographical imaginaries, Human trafficking.

\section{INTRODUCCIÓN}

La trata de personas con fines de explotación sexual es un problema que presenta diversas aristas para su estudio. Si bien existe desde el siglo pasado literatura dedicada a esta problemática, es a partir de la Convención de las Naciones Unidas contra la delincuencia organizada transnacional y sus protocolos que se define de manera internacional. Celebrada en el año 2000 en Palermo (Italia) y ratificada por Argentina por la ley 25.632 de 2002 , en su artículo ${ }^{\circ} 3$ define que:

...por "trata de personas" se entenderá la captación, el transporte, el traslado, la acogida o la recepción de personas, recurriendo a la amenaza o al uso de la fuerza u otras formas de coacción, al rapto, al fraude, al engaño, al abuso de poder o de una situación de vulnerabilidad o a la concesión o recepción de pagos o beneficios para obtener el consentimiento de una persona que tenga autoridad sobre otra, con fines de explotación. Esa explotación incluirá, como mínimo, la explotación de la prostitución ajena 
u otras formas de explotación sexual, los trabajos o servicios forzados, la esclavitud o las prácticas análogas a la esclavitud, la servidumbre o la extracción de órganos... (Protocolo de Palermo, 2003, p. 2)

Esta definición fue tomada para el análisis del fenómeno por diversos organismos, ya sea estatales o de la sociedad civil como así también por la literatura académica y periodística. Sin embargo, si bien no será desarrollado en este artículo, es interesante remarcar que las interpretaciones que se realizan sobre los alcances de esta definición son diversas. Esto trae como consecuencia que diferentes situaciones sean consideradas como casos de trata de personas ${ }^{1}$ por algunos actores y no por otros.

En este artículo interesa particularmente reconocer las representaciones de los espacios de trata de personas que la entienden a partir de la definición acordada en la Convención de Palermo. Antes de introducir la noción lefebvriana de representación del espacio, es importante aclarar que el período elegido para el análisis de dichas representaciones abarca desde el año 2008 a 2018. Este criterio responde a que la sanción de la ley sobre la prevención y sanción de la trata de personas y asistencia a sus víctimas (Ley 26.364) fue sancionada y promulgada en Argentina en 2008. En consecuencia, es a partir de este año que se crean organismos estatales que tendrán por objetivo, entre otros, la creación de información sobre la problemática a escala nacional. Dicha información será presentada a través de informes que mostrarán determinadas representaciones del espacio de la trata de personas. A su vez, diferentes organismos de la sociedad civil también han tomado la tarea de producir información sobre la problemática.

\section{LA PRODUCCIÓN DEL ESPACIO DE LA TRATA DE PERSONAS CON FINES DE EXPLOTACIÓN SEXUAL}

Antes de adentrarse en el análisis de las representaciones mencionadas anteriormente, es preciso presentar brevemente la teoría sobre la producción del espacio de Henri Lefebvre, a partir de la cual serán analizadas. Este autor francs propone considerar al espacio como un producto de las relaciones sociales, el cual, como tal, interviene en la propia producción. De esta manera, el espacio no es aquí concebido como pasivo o mero contenedor, sino que es una instancia, entre otras, de la totalidad social:

El espacio ya no puede concebirse como pasivo, vacío, como no teniendo más sentido que -al igual que sucede con los otros "productos" - ser intercambiado, consumido o suprimido. En tanto que producto, mediante interacción o retracción, el espacio interviene en la producción misma... (Lefebvre, 1974, pp. 55-56)

A su vez, el espacio adoptará particularidades de acuerdo a cada modo de producción -entendidos estos como relaciones sociales de producción- imperante. De esta forma, el sistema de producción capitalista genera un espacio particular, que difiere del espacio de otros modos de organización de la sociedad. Sumado a esto, el capitalismo ha ido modificando sus relaciones y podría pensarse que existe un espacio específico desarrollado por el capitalismo neoliberal. Es decir, cada etapa del capitalismo generará su propio espacio, aun cuando el modo de producción sea el capitalista, en términos generales. Así, actualmente, el capitalismo neoliberal utiliza los espacios producidos en otras etapas del sistema.

Si retomamos la propuesta de Henri Lefebvre para conceptualizar la producción del espacio, el autor propone una tríada dialéctica compuesta por el espacio percibido, el concebido y el vivido. En términos espaciales, esta tríada puede expresarse como práctica del espacio, representaciones del espacio y espacios de representación.

La práctica del espacio, primer elemento de la tríada, hace referencia a la "producción y [la] reproducción, lugares específicos y conjuntos espaciales propios de cada formación social; práctica que asegura la continuidad en el seno de una relativa cohesión" (Lefebvre, 1974, p. 92). Como señala Schmid, el concepto de las prácticas espaciales 
...designa la dimensión material de la actividad social e interacción. La clasificación espacial significa centrarse en el aspecto de la simultaneidad de actividades. (...) En términos concretos, se podría pensar en las redes de interacción y comunicación a medida que surgen en la vida cotidiana (por ejemplo, la conexión diaria de residencia y lugar de trabajo) o en el proceso de producción (relaciones de producción e intercambio) (traducción propia) (Schmid, 2008, p. 36)

Por su parte, las representaciones del espacio -concepto que se utilizará aquí para pensar las cartografías sobre la trata de personas- "se vinculan a las relaciones de producción, al 'orden' que imponen y, de ese modo, a los conocimientos, signos, códigos y relaciones 'frontales'" (Lefebvre, 1974, p. 92). Estas representaciones se corresponden con el espacio concebido por "científicos, planificadores, urbanistas, tecnócratas fragmentadores, ingenieros sociales y hasta el de cierto tipo de artistas próximos a la cientificidad, todos los cuales identifican lo vivido y lo percibido con lo concebido" (Lefebvre, 1974, p. 97). En consecuencia, "las disciplinas especializadas que se ocupan de la producción de estas representaciones son la arquitectura y la planificación, pero también las ciencias sociales (y aquí la geografía es de especial importancia)" (Schmid, 2008, p. 37).

De esta manera, el espacio concebido o, en términos espaciales, las representaciones del espacio se constituyen como la producción de saber legítimo y se difunden como tales. En este punto, es interesante retomar el planteo de David Harvey presentado por Colombo -sobre las consecuencias que provoca ejercer el poder de control sobre las representaciones del espacio-, que será de gran utilidad para pensar la producción de las cartografías sobre la trata de personas:

El control y/o manipulación sobre las representaciones espaciales es igual o más importante que el control sobre la materialidad del espacio; en otras palabras, quien maneje las representaciones podrá manejar también la dimensión material del espacio (Harvey, 1990) (Colombo, 2017, p. 72).

El tercer concepto de la tríada, los espacios de representación, hace referencia al

...espacio vivido a través de las imágenes y los símbolos que lo acompañan, y de ahí, pues, el espacio de los "habitantes", de los «usuarios», pero también el de ciertos artistas y quizá de aquellos novelistas y filósofos que describen y sólo aspiran a describir. Se trata del espacio dominado, esto es, pasivamente experimentado, que la imaginación desea modificar y tomar (Lefebvre, 1974, pp. 97-98).

Si bien la producción del espacio puede ser entendida en estos tres momentos -que están dialécticamente interrelacionados-, por una cuestión del estado de avance de la investigación y luego de realizar una división exclusivamente analítica, el artículo se centra en una de esas dimensiones: las representaciones del espacio.

\section{LAS REPRESENTACIONES DEL ESPACIO DE LA TRATA DE PERSONAS CON FINES DE EXPLOTACIÓN SEXUAL}

Estudiar las representaciones del espacio de la trata de personas con fines de explotación sexual para Argentina requiere relevar los discursos sobre dichos espacios y las concepciones que existen sobre los mismos, es decir, cómo fueron concebidos. A modo de contribución para la reconstrucción de esos discursos, en el presente trabajo se estudian las cartografías de la trata de personas, elaboradas por diferentes organismos nacionales y asociaciones civiles que se constituyen como actores hegemónicos en la producción del conocimiento espacial de la trata de personas con fines de explotación sexual en Argentina.

En términos metodológicos se ha llevado a cabo un análisis documental a través de la revisión extensa de la bibliografía académica que existe sobre la temática: las producciones cartográficas de las organizaciones de la sociedad civil (organismos no gubernamentales, asociaciones civiles, movimientos sociales y organizaciones políticas); los medios gráficos de tirada nacional así como los informes oficiales de organismos internacionales y de instituciones nacionales.

Es importante aclarar que para el análisis de las cartografías se ha adoptado una perspectiva crítica, es decir, que los mapas son considerados como discursos y no como reflejos sobre el papel de "la realidad". En 
consecuencia, las figuras cartográficas aquí analizadas son algunas de las tantas representaciones espaciales posibles sobre la trata de personas. El hecho de que las cartografías realizadas por organismos estatales y asociaciones civiles sean las que se presentarán más adelante y no otras evidencia el vínculo que existe entre la cartografía y el poder, en este caso, la búsqueda de instalar o difundir una mirada específica (que se constituirá como hegemónica) sobre el fenómeno de la trata.

Luego de la recopilación de información cartográfica y del análisis documental se han encontrado prolíferas cartografías (más de cincuenta) que abordan diferentes dimensiones de la trata de personas. Sin embargo, es interesante remarcar que una parte de las producciones académicas sobre el tema no incluye representaciones cartográficas del recorte espacial que abordan en su estudio. Por su parte, las organizaciones de la sociedad civil y los medios de comunicación han producido o presentado mapas que representan a la trata de personas a diferentes escalas.

Un primer análisis de las cartografías relevadas permite diferenciar tres dimensiones representadas: 1) la situación nacional en relación a la legislación vigente sobre la explotación sexual y la capacitación a agentes estatales para su detección; 2) las redes de trata de personas (indicando puntos de origen o destino de trata o las rutas de tránsito), y 3 ) cantidad de víctimas detectadas, a diferentes escalas, como pueden encontrarse en los informes Global report on trafficking in persons elaborados por la Oficina de Naciones Unidas contra la Droga y el Delito de 2009 a 2018.

Empero, por una cuestión de extensión, el artículo se centrará en el análisis de algunas de las cartografías del segundo grupo, que abordan de manera directa la dimensión espacial. Es decir, si bien todas las cartografías se constituyen como representaciones del espacio de la trata de personas y, en consecuencia, producen el espacio de la trata, las que forman parte del segundo grupo se enfocan explícitamente en representar la dimensión espacial del fenómeno.

Dentro de las representaciones del espacio que aportan datos específicos sobre la espacialidad de las redes de trata de personas en Argentina (ya sea indicando puntos de origen o destino de trata o las rutas de tránsito) se destacan las elaboradas por la Unidad de Asistencia en Secuestros Extorsivos y Trata de Personas (UFASE) junto con el Instituto de Estudios Comparados en Ciencias Penales y Sociales (INECIP), quienes en 2012 presentaron el informe "La trata sexual en Argentina". La primera representación del espacio que figura en él se presenta a continuación: 
FIGURA 1

Rutas de la trata de personas con fines de explotación sexual

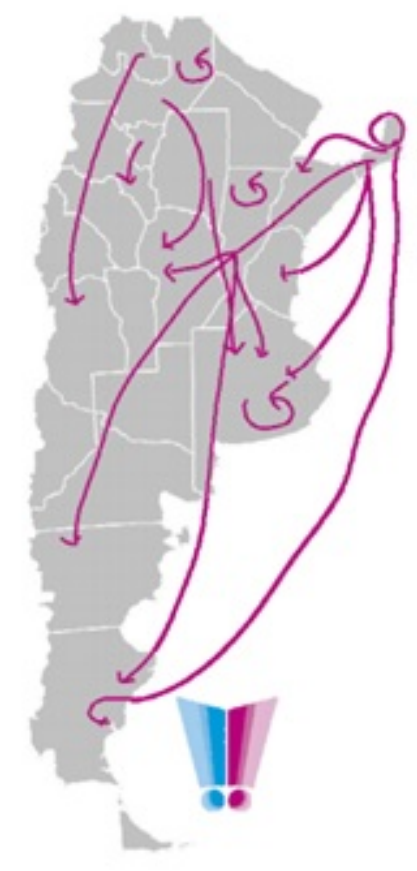

Datos construidos a partir del relevamiento de causas, UFASE-INECIP

(El mapa solamente indica circuitos conocidos, pero no da cuenta de la afluencia de los mismos)

Fuente: UFASE-INECIP (2012, p. 30)

La figura 1 (que aunque es analizada como tal no es estrictamente una cartografía, dado que no está georreferenciada ni presenta la escala, entre otros elementos) permite crear una primera impresión sobre el despliegue espacial de la trata de personas en Argentina. Se muestra que el mismo se concentra en el norte (Misiones) y centro (Santa Fe) de Argentina, con algunas rutas hacia el sur del país. Además, la figura 1 permite reconocer las siguientes rutas de trata de personas: a) desde Salta hacia Salta y Córdoba (pasando por Santiago del Estero); b) desde Jujuy hacia Mendoza (pasando por Salta, Catamarca, La Rioja y San Juan); c) desde Tucumán a Catamarca; d) desde Santa Fe a Santa Fe, Buenos Aires, Santa Cruz, Córdoba y Chubut (pasando por Córdoba, San Luis, La Pampa y Río Negro); e) desde Santiago del Estero a Buenos Aires (pasando por Córdoba y Santa Fe); f) desde Misiones a Corrientes (por Paraguay) y a Santa Cruz; a Buenos Aires y Entre Ríos (por Brasil) y a Santa Fe (por Corrientes); h) dentro de la Provincia de Buenos Aires.

Es interesante remarcar que la figura 1 muestra provincias en las que no hay registro de casos de trata de personas con fines de explotación sexual, tales como La Pampa, San Luis, Neuquén, Tierra del Fuego, Formosa, Chaco y La Rioja.

La segunda representación que figura en el informe mencionado es la siguiente: 
FIGURA 2

Principales zonas de explotación, según causas judiciales

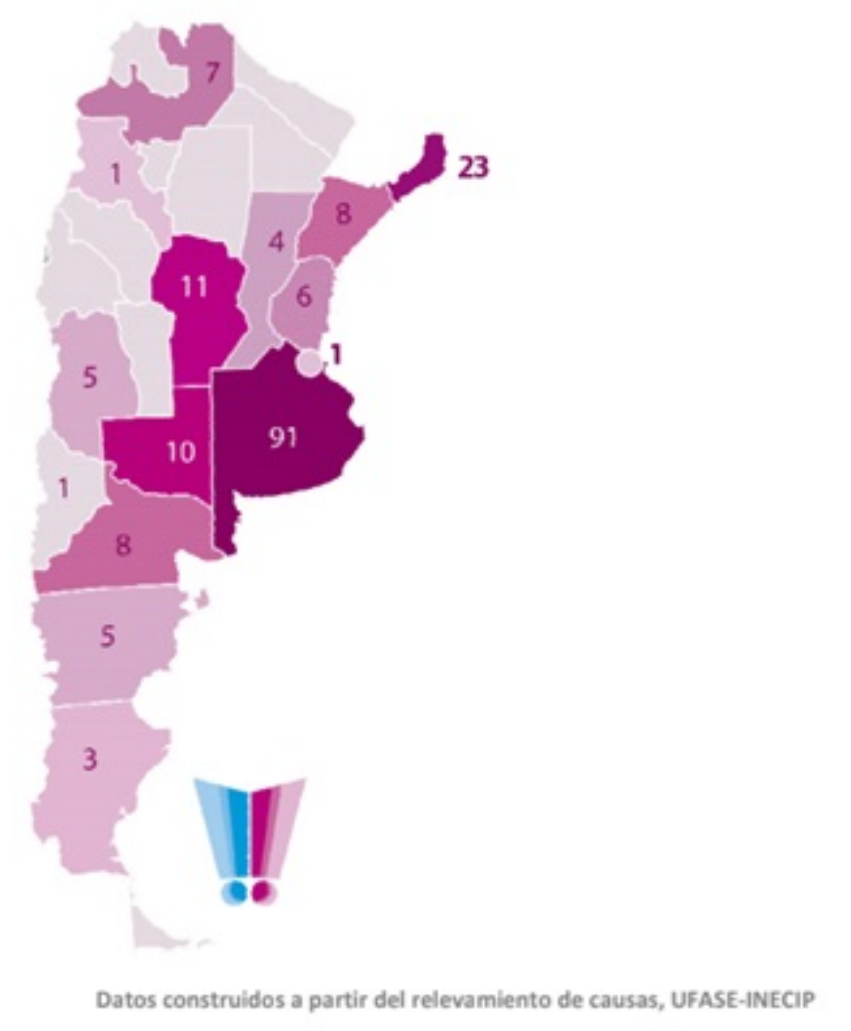

Fuente: UFASE-INECIP (2012, p. 36)

Según esta figura, Buenos Aires, Misiones, Córdoba y La Pampa se constituyen en las principales zonas de explotación sexual de las personas. Es interesante remarcar la diferencia con la figura 1, en la que la provincia de La Pampa no figura como punto de destino de las rutas de la trata y aquí es resaltada. En la figura 2 se muestra un desplazamiento respecto de la figura 1: aquí, el centro de Argentina (Buenos Aires, principalmente) se constituye como el lugar de explotación sexual y el norte del país no figura como tal, a excepción de Misiones.

$\mathrm{Al}$ igual que en la primera figura, aquí también hay provincias que se presentan sin estar involucradas en la trata de personas, al menos como lugares donde se concreta la explotación, como son Jujuy, Tucumán, San Luis, Tierra del Fuego, La Rioja, San Juan, Santiago del Estero, Formosa y Chaco.

Por su parte, la tercera representación que figura en el informe elaborado por la UFASE e INECIP también muestra las principales zonas de explotación, pero esta figura está elaborada sobre una fuente diferente a la tercera. 
FIGURA 3

Principales zonas de explotación, según medios de comunicación

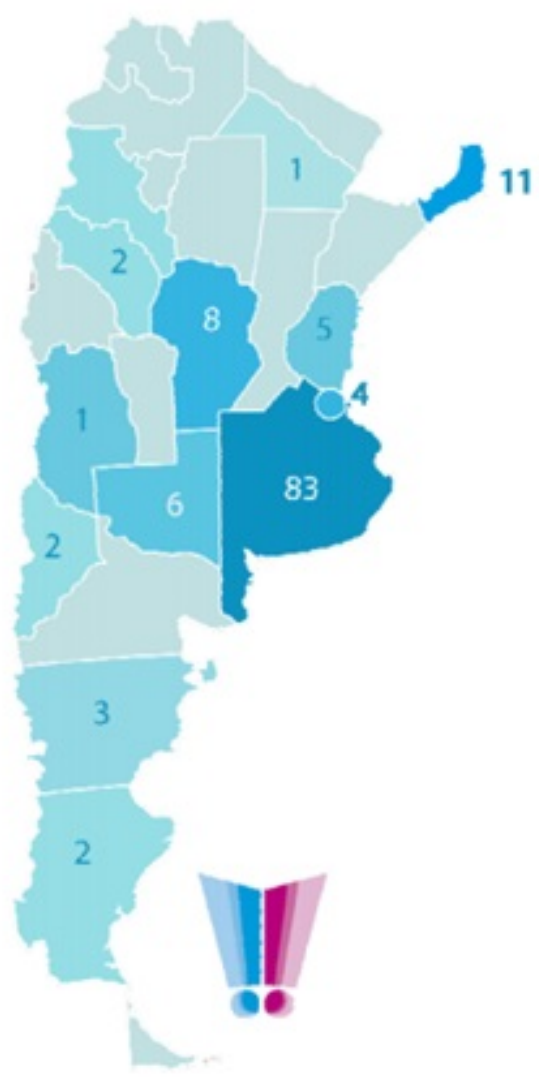

Datos construidos a partir del relevamiento de medios -INECIP

Fuente: UFASE-INECIP (2012 p. 38)

En esta figura, la provincia de Buenos Aires tiene una predominancia sobre las demás y pasa a constituirse como el principal lugar de explotación sexual. La siguen Córdoba y Misiones; esta última es señalada también en la figura 2 como destino de las rutas de trata de personas. Es interesante la repetición -respecto de la figura 2- de las provincias que no se muestran como lugares de explotación: Tierra del Fuego, San Luis, San Juan, Santiago del Estero, Jujuy, Tucumán y Formosa. A su vez, a diferencia de la figura 2, hay provincias que no figuran como zonas de explotación: Río Negro, Salta, Corrientes y Santa Fe. La provincia de Catamarca aparece resaltada como una zona de explotación, pero no se brinda un número de la cantidad de casos relevados, lo que dificulta el análisis. Tanto la figura 2 como la 3 coinciden en indicar a las provincias de Buenos Aires, Misiones, La Pampa y Córdoba como las principales involucradas en la explotación sexual.

Por su lado, en 2010, la Asociación Civil Unidos por la Justicia elaboró el Manual de intervención de casos de trata de personas en Argentina, financiado por la Oficina para Monitorear el Tráfico de Personas del Departamento de Estado de Estados Unidos. En él se muestran dos representaciones del espacio sobre la trata de personas con fines de explotación sexual. 
FIGURA 4

Rutas de trata desde el exterior hacia provincias de Argentina

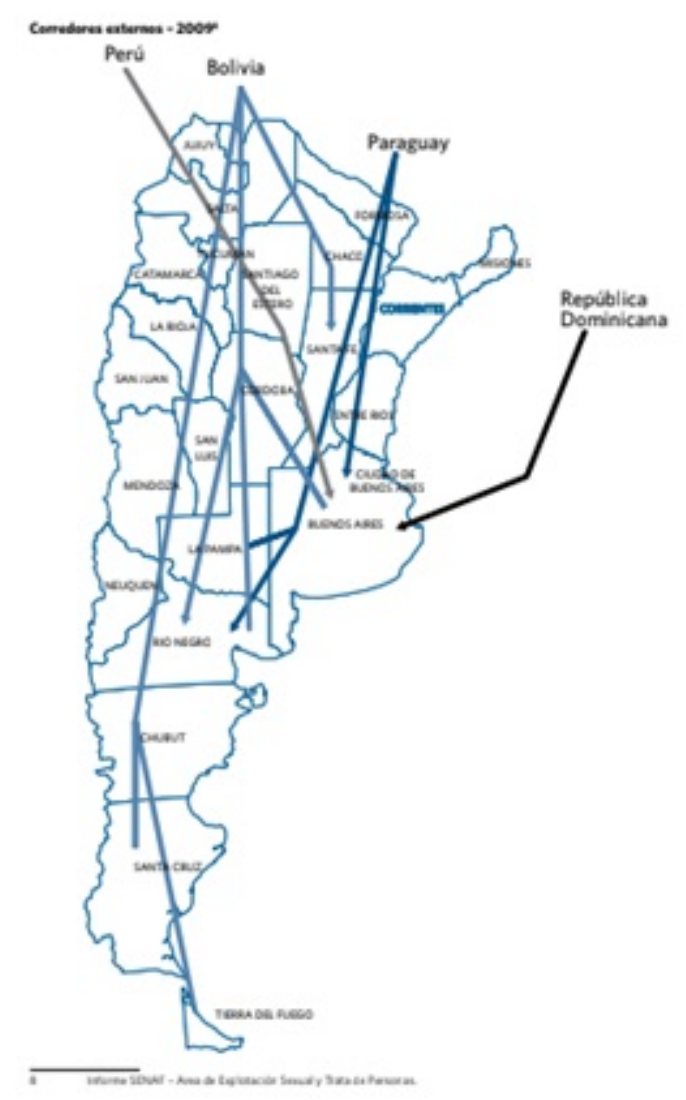

Fuente: Asociación Civil Unidos por la Justicia (2010, p. 27)

La figura 4 indica que las rutas de la trata de personas que tienen como destino a Argentina se inician en Perú, Bolivia, Paraguay y República Dominicana. Así, desde Paraguay se inicia una ruta que cruza por las provincias de Jujuy, Salta, Tucumán, Santiago del Estero, Córdoba y Santa Fe para terminar en Buenos Aires. Desde Bolivia hay tres rutas posibles: a) una con destino Chubut, que atraviesa Jujuy, Salta, Tucumán, Catamarca, La Rioja, San Luis, Mendoza, La Pampa, Neuquén y Río Negro, y que luego, desde Chubut, continua hasta San Cruz por un lado, y, por otro, recorre la provincia de Santa Cruz para terminar en Tierra del Fuego; b) otra con destino Córdoba, que cruza por Jujuy, Salta y Santiago del Estero, pero por un camino diferente a la ruta anterior, y que desde Córdoba se divide en otras tres rutas: una hacia Río Negro por San Luis y La Pampa, otra con el mismo destino pero que solo pasa por La Pampa, y una tercera con destino a Buenos Aires, que pasa por el sur de Santa Fe, y c) una con destino a Santa Fe, que atraviesa las provincias de Salta y Chaco. Por su parte, las rutas iniciadas en Paraguay muestran a Buenos Aires como uno de los destinos posibles, si se traza un camino por Formosa, Chaco, Corrientes y Entre Ríos, y, desde Paraguay, a su vez, se trazan otras rutas que atraviesan las provincias de Formosa, Chaco y Santa Fe hasta llegar a Buenos Aires, donde se bifurcan una con destino a La Pampa y otra hacia Río Negro. Por su parte, desde República Dominicana se marca otra ruta con destino Buenos Aires, aunque no se indica su recorrido. En esta figura se muestra que San Juan es la única provincia que no presenta una ruta de trata de personas.

El Manual de intervención de casos de trata de personas en Argentina también contiene la siguiente representación: 
FIGURA 5

Rutas de trata internas de Argentina

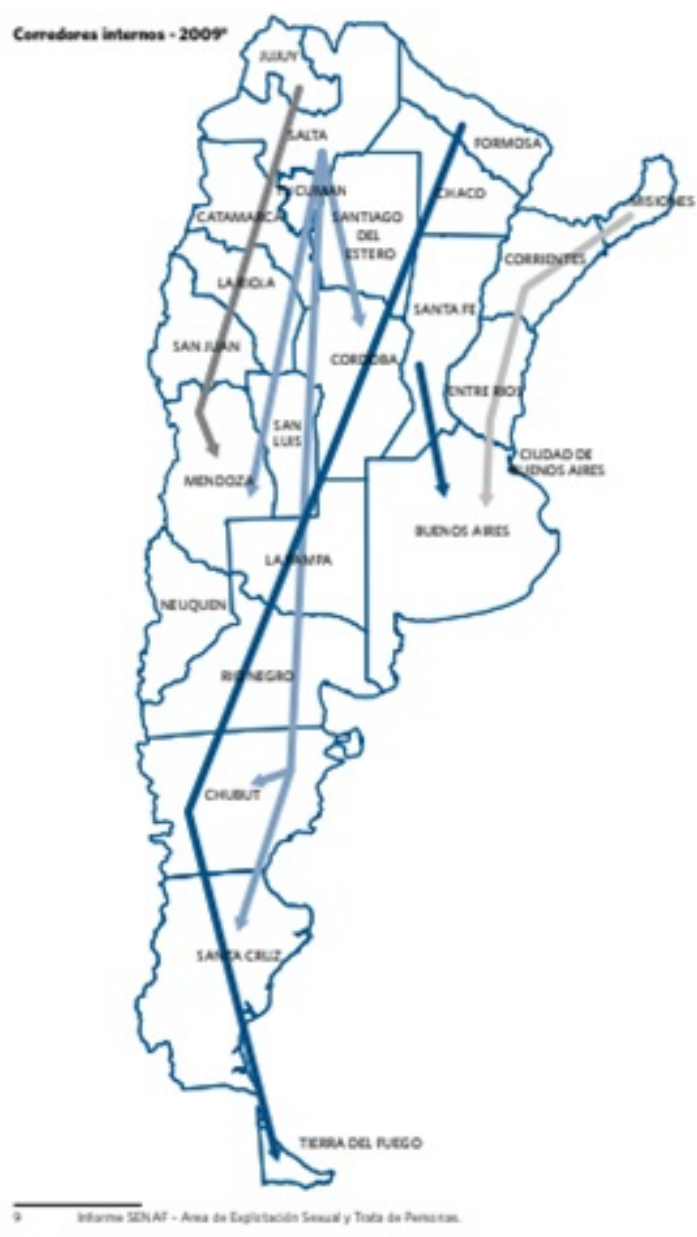

Fuente Asociación Civil Unidos por la Justicia (2010, p. 28)

En relación a las rutas internas, en la figura 4 se representan cinco provincias argentinas desde donde se inician estas rutas. Desde Jujuy se traza una ruta que atraviesa a Salta, Catamarca, La Rioja, San Juan y termina en Mendoza, y desde Misiones otra ruta hacia Buenos Aires, que atraviesa por Corrientes y Entre Ríos; otra va desde Santa Fe a Buenos Aires. A su vez, desde Formosa se puede reconocer una ruta que pasa por Chaco, Santiago del Estero, Córdoba, La Pampa, Río Negro y Chubut, para desde allí dirigirse a Tierra del Fuego, atravesando Santa Cruz. Desde Salta se inician tres rutas: a) hacia Mendoza, pasando por Tucumán, Catamarca, La Rioja y San Luis; b) hacia Córdoba, pasando por Santiago del Estero, c) y hacia Chubut y Santa Cruz, compartiendo el camino por Tucumán, Santiago del Estero, Córdoba, San Luis, La Pampa y Río Negro. De esta forma, según la figura 4, la única provincia que no está señalada por una ruta de trata de personas es Neuquén.

\section{AlgunOS INTERRogantes SOBRE LAS REPRESENTACIONES ESPACIALES}

Para superar la descripción realizada de estas cuatro figuras que se proponen como representaciones del espacio de la trata de personas - retomando además el planteo de Harvey acerca de que quien manejare las representaciones del espacio puede manejar tambin el control material del espacio-, interesa plantear algunos interrogantes sobre las mismas. 
Con respecto a las producciones cartográficas, elaboradas desde el organismo nacional encargado de la recopilación y producción de información sobre la trata de personas (UFASE) y por una asociación civil financiada por Estados Unidos, pueden realizarse ciertos interrogantes sobre diferentes ejes de análisis.

En relación a las rutas trazadas cabe preguntarse: ¿por qué se representan circuitos pero no se indica la afluencia de estos? ¿Cuál es la intensidad de los flujos marcados por las flechas? ¿Se considera que un circuito es el tramo entre un punto de origen y uno de llegada? ¿Se representan con exactitud las trayectorias recorridas (algunas, incluso, por el mar Argentino) o meramente se marca la unión de puntos entre provincias (o dentro de una misma provincia)? ¿Quiénes recorrieron esas rutas? ¿Bajo qué modalidad se produjo el traslado? ¿Los cruces entre las rutas que se dibujan en la figura están indicando conexiones entre los circuitos?

Además es posible preguntarse por el alcance de las redes, por ejemplo: ¿los puntos de origen y destino de cada ruta se corresponden con una localidad específica de cada provincia o se quiere hacer referencia a la provincia entera? A su vez, ¿puede pensarse que se representa al espacio como un mero contenedor de puntos y líneas, desdibujando su rol productor de lo social?

Si miramos la información por provincias, aparece la duda acerca de los motivos por los que se muestran algunas provincias sin rutas de trata, y otras, como Misiones y Santa Fe, figuran como lugares desde donde se inician las rutas con mayor cantidad de destinos. ¿Esta información tiene que ver con lo que puede leerse de las fuentes tomadas (causas judiciales y medios periodísticos) para realizar la figura o es lo que ocurre en el plano material de la trata?

\section{LA CAMPAÑA ANTITRATA}

Las representaciones del espacio de la trata de personas aquí analizadas pueden ser pensadas dentro de la campaña antitrata ${ }^{2}$ que viene desarrollándose en los ltimos años iniciada por el Departamento de Estado de Estados Unidos y que hoy se ha expandido a escala global (Varela, 2013). Dicha campaña consiste en una serie de instrumentos legales e institucionales que buscan sancionar y erradicar la trata de personas a travs de políticas humanitaristas que regulan la existencia de los seres humanos. Diversos actores, como las organizaciones sin fines de lucro, los Estados o los organismos internacionales, desarrollan una serie de prácticas que tienen por fin, al menos en el plano del discurso, prestar ayuda a aquellos seres humanos que se encuentran desprotegidos o en una situación de desventaja. De este modo, en lugar de otorgarles un lugar de agencia, se crean sujetos que necesitan ser ayudados:

...las desigualdades se borran en beneficio de la exclusión, la dominación se transforma en malestar, la injusticia se nombra en las palabras del sufrimiento, la violencia se expresa en términos de traumatismo (Fassin, 2016, p. 17).

Así, se construye una realidad evidente que justifica la intervención: es preciso actuar para ayudar a los sujetos que evidentemente se encuentran en una situación de desventaja. Al desplegar los sentimientos morales en las políticas gubernamentales se genera una retórica que puede pensarse como "política de la compasión”, y, a partir de la legitimación que esa política brinda, se llevan a cabo prácticas gubernamentales que no se traducen en la equiparación de derechos, sino que, por el contrario, aumentan la desigualdad: "la política de la compasión es una política de la desigualdad” (Fassin, 2016, p 12). Dentro de estas políticas estatales pueden encontrarse las referidas a la trata de personas.

\section{A MODO DE CIERRE}

En el artículo se han analizado cuatro representaciones del espacio que producen espacialmente el fenómeno de la trata de personas en Argentina. Junto a esto, se han planteado brevemente las principales líneas políticas de construcción de la campaña antitrata. En consecuencia, cabe preguntarse entonces si las 
representaciones del espacio aquí analizadas no estarían constituyendo parte de los discursos antitrata de la mencionada campaña, lo que aportaría a la construcción de esa realidad que vuelve evidente la intervención estatal, generalmente por parte del aparato represivo del Estado.

Alicia Lindón y Daniel Hiernaux (2012) analizan los imaginarios sociales y argumentan que son parte constitutiva de la trama social y, en consecuencia, de lo espacial. Si consideramos que los imaginarios construyen sentidos, dicha teoría plantea un vínculo estrecho entre estos y las imágenes:

Sin duda, esa imagen no es lo mismo que el imaginario. Esa imagen representa la figuración en la cual se sintetiza el imaginario. El imaginario requiere de esa imagen como su concreción, pero al mismo tiempo el imaginario desborda a la imagen. El imaginario es toda esa trama de sentido tejida en torno a cada pieza de la imagen. La imagen es interna a los sujetos. Una expresión de ello es que el lector la puede reproducir mentalmente sin dificultad. Pero resulta que esa imagen también se ha materializado como una expresión gráfica, que ha sido reproducida (Lindón y Hiernaux, 2012, p. 17)

Al leer las imágenes cartográficas sobre la trata de personas, aunque no existe un discurso del todo homogéneo en las mismas, puede pensarse que el conjunto del territorio argentino está involucrado en la trata de personas con fines de explotación sexual. La cantidad de líneas trazadas que muestran rutas puede aportar a los imaginarios espaciales, geográficos, la idea de que las redes de trata son omnipresentes y que requieren de la intervención estatal para su erradicación.

Por último, se considera que para poder producir el espacio de la trata de personas desde una perspectiva de género y alejada del planteo de la campaña antitrata, es necesario utilizar herramientas novedosas que permitan crear cartografías que ilustren e informen sobre este fenómeno en su total complejidad. Junto a esto se evidencia el requerimiento de recuperar la experiencia de los sujetos que han sido o siguen siendo víctimas de explotación sexual para poder caracterizar al delito de la trata de personas desde una perspectiva integral, $\mathrm{y}$, por tanto, que incluya la dimensión espacial como un componente esencial del fenómeno.

\section{REFERENCIAS}

Colombo, P. (2017). Espacios de desaparición. Vivir e imaginar los lugares de la violencia estatal (Tucumán, 1975-1983). Buenos Aires: Miño y Dávila.

Fassin, D. (2016). La razón humanitaria. Una historia moral del tiempo presente. Buenos Aires: Prometeo.

Lefebvre, H. ([1974] 2013). La producción del espacio. Madrid: Capitán Swing.

Lindón, A., y Hiernaux, N. (2012). Renovadas intersecciones: la espacialidad y lo imaginario. En A. Lindón y N. Hiernaux (Dir.), Geografias de lo imaginario (pp. 9-28) Barcelona: Anthropos Editorial; México: Universidad Autónoma Metropolitana, Iztapalapa.

Oficina de Naciones Unidas contra la Droga y el Delito (2009). Global report on trafficking in persons. Recuperado de http://www.unodc.org/documents/human-trafficking/Global_Report_on_TIP.pdf

Oficina de Naciones Unidas contra la Droga y el Delito (2016). Global report on trafficking in persons. Recuperado de https://www.unodc.org/documents/data-and-analysis/glotip/2016_Global_Report_on_Trafficking_in_P ersons.pdf

Protocolo para prevenir, reprimir y sancionar la trata de personas, especialmente mujeres y niños, que complementa la Convención de las Naciones Unidas contra la Delincuencia Organizada Transnacional (2000). Palermo, Italia. Recuperado de http://www.ohchr.org/Documents/ProfessionalInterest/ProtocolTraffickingInPersons_sp.pdf

Schmid, C. (2008). Henri Lefebvre's theory of the production of space: towards a three-dimensional dialectic. En Goonewardena (Ed.), Space, difference, everyday life: reading Henri Lefebvre. (pp. 27-45) New York: Routledge.

Unidad de Asistencia en Secuestros Extorsivos y Trata de Personas e Instituto de Estudios Comparados en Ciencias Penales y Sociales (2012). La trata sexual en Argentina. Recuperado de https://www.mpf.gob.ar/protex/tipo_ de_recurso/informe-estadistico/ 
Unidos por la justicia Asociación Civil (2010). Manual de intervención de casos de trata de personas en Argentina. Recuperado de http://www.fundacionmariadelosangeles.org/images/pdf/manual-de-intervencion-de-casos-de -trata-de-personas-en-argentina.pdf

Varela, C. I. (2013). De la "letra de la ley" a la labor interpretante: la "vulnerabilidad" femenina en los procesos de judicialización de la ley de trata de personas (2008-2011). Cadernos Pagu, (41), 265-302. Recuperado de https: //periodicos.sbu.unicamp.br/ojs/index.php/cadpagu/article/view/8645102

\section{Notas}

1. A partir de aquí, cuando se haga mención a la trata de personas se estará refiriendo a aquella que tiene por fin la explotación sexual.

2. Utilizo el término "antitrata" para dar cuenta de un campo heterogéneo de organizaciones sociales -tanto no gubernamentales como colectivos autogestionados- con distintas trayectorias y experiencias formativas, cuyo rasgo común es proponerse acciones (de distinta índole) de vigilancia y combate a la trata de personas" (Varela, 2013, p. 271). 